\title{
KHẢO SÁT SỰ HÀI LÒNG CỦA NHÂN VIÊN Y TẾ ĐỐI VớI CÁC DẠNG THUỐC SEVOFLURANE ĐANG LƯU HÀNH TẠI VIỆT NAM
}

\author{
Công Quyết Thắng1, Đỗ Văn Dũng², Nguyễn Thị Thu Thủy ${ }^{2 *}$, \\ Nguyễn Vũ Lan Chi ${ }^{1}$, Phạm Anh Tuấn ${ }^{3}$, Nguyển Đức $\mathrm{Nam}^{4}$, \\ Phạm Thị Minh Thư ${ }^{5}$, Nguyễn Thị Hồng $\mathrm{Nhi}^{5}$, \\ Nguyễn Thị Kim Hiệp ${ }^{6}$, Nguyễn Văn Tiến ${ }^{7}$, Vũ Văn Hoàng ${ }^{7}$
}

\section{TÓM TẮT}

Đăt vấn đề: Sevoflurane là môt tronq nhữnq thuốc qây mê (GM) hô hấp đước sử dunq phổ biến nhất. Sư hài lònq $(\mathrm{HL})$ của nhân viên y tế (NVYT) đối với các danq sevoflurane tai Viêt Nam là tiêu chí quan trong trong lưa chọn thuốc. Mục tiêu: Khảo sát sự HL của NVYT đối với các dạng thuốc sevoflurane đang được lưu hành tại Việt Nam. Đối tượng và phương pháp nghiên cứu: N̉ghiên cứu mô tả cắt ngang trên đối tượng bác sĩ GM (BSGM) và kỹ thuật viên GM (KTVGM) tại 5 bệnh viện ở Việt Nam, trong đó sự HL tổng thể cho từng thuốc được đánh giá dựa trên sự HL và mức độ quan trọng trển từng tiêu chí sử dụng thuốc bằng thang đo Likert 5 mức độ. Kết quả: Khảo sát trên 96 BSGM và 118 KTVGM, đề tài ghi nhận điểm HL đối với sevoflurane biệt dược gốc (BDG) cao hơn generic ở cả $B S(4,29$ so với 3,$67 ; p=0,000)$ và KTV GM $(3,83$ so với 3,$17 ; p=0,000)$. Xét trên từng tiêu chí, bức tranh tương tự ghi nhận, trừ tiêu chí giá thuốc không ghi nhân sự khác biệt trong điểm $\mathrm{HL}$ giữa $B D G$ và generic ở cả $B S$ và KTV GM. Kết luận: Sự hài lòng của $B S G M$ và KTVGM đối với sevoflürane biệt dược gốc cao hơn thuốc generic ở tất cả các tiêu chí (trừ tiêu chí giá thuốc) và tổng điểm chung.

Tư khóa: sự hài lòng, sevoflurane, biệt dược gốc, generic

\section{SUMMARY}

\section{SURVEILLANCE OF HEALTH PROFESSIONALS' SATISFACTION WITH DIFFERENT FORMS OF SEVOFLURANE IN VIETNAM}

Background: Sevoflurane is one of the most common used anesthetic agents. The satisfaction of medical staffs with sevoflurane forms in Vietnam is an important criterion in drug selection. Objectives: Survey of health professionals' satisfaction with available forms of sevoflurane in Vietnam. Methods: The multi-center study investigated the satisfaction of anesthesiologists and anesthesia technicians towards

${ }^{1}$ Hội Gây mê Hồi sức Việt Nam

${ }^{2}$ Đại học Y Dược Thành phố Hồ Chí Minh

${ }^{3}$ Bềnh viện Việt Đức

${ }^{4}$ Bệnh viện Đại học Y dược Thành phố Hồ Chí Minh

${ }^{5}$ Bềnh viền Đại học Y dược Huế

${ }^{6}$ Bệnh viện Chơ Rẫy

'Bềnh viên Hữu Nghi

Chịu trách nhiệm chính: Nguyễn Thị Thu Thủy

Email: nguyenthuthuy@ump.edu.vn

Ngày nhận bài: 16.11.2020

Ngày phản biên khoa học: 5.01 .2021

Ngày duyệt bài: 19.01.2021 sevoflurane's different forms in 5 hospitals in Vietnam. Overall satisfaction for a particular drug was assessed based on satisfaction index and importance index on each criterion for each respective drug on a 5-level Likert scale. Results: Surveying 96 anesthesiologists and 118 anesthesia technicians, the study noted that the satisfaction score for brand name sevoflurane was higher than generic drug for both anesthesiologists (4.29 versus $3.67, \mathrm{p}=0.000)$ and anesthesia technicians (3.83 versus $3.17, \mathrm{p}=0.000)$. Considering each individual criterion, $\mathrm{a}$ similar picture is also noted, except for the criterion of drug price, in which there is no statistical difference in satisfaction score between sevoflurane brand-name and generic in both anesthesiologists and anesthesia technicians. Conclusions: Anesthesiologists and anesthesia technicians' satisfaction with the brand-name sevoflurane was higher than generic in all criteria (except for drug price) and overall score.

Keywords: satisfaction, sevoflurane, brand-name, generic

\section{I. ĐĂT VẤN ĐỀ}

Sevoflurane là một trong những thuốc gây mê đường hô hấp được sử dụng phổ biến nhất trong các thuốc gây mê, đặc biệt là gây mê ngoại trú(1), với nhiều ưu điểm như độ tan trong máu thấp, nhañh chóng gây mê, không gây kích ứng, có mùi dễ chịu, an toàn cho các bênh nhân mắc các bệnh liên quan đến tim mạch, không gây tỉnh trong quá trình gây mê...(2). Nhiêuu nghiên cứu so sánh sevoflurane biệt dược gốc và thuốc generic về độ ổn định, tính hiệu quả và tính an toàn ${ }^{(3)}$; về thành phân điêu chế thuốc ${ }^{(4)}$, về hiệu quả lâm sàng(5) với kết quả cho thây không có khác biệt đáng kể giữa thuốc generic so với thuốc gốc ${ }^{(3-5)}$. Tuy nhiên sư hài lòng $(\mathrm{HL})$ của nhân viên y tế (NVYT) là tiêu chí quan trọng trong lựa chọn thuốc, đặc biệt là đối với thuốc gây mê có khả năng ảnh hưởng đến sự an toàn của NVYT và môi trường xung quanh. Chủ đề này vẫn chưa được thực sự quan tâm hiện nay. Tại Việt Nam, hiện tại có 3 chế phẩm sevoflurane đang được lưu hành và sư dụng bao gôm: Sevorane Sol (Abbvie), Sevoflurane (Baxter) và Seaoflura (Piramal) với giá thành dao động từ 1,723 triệu đến 3,578 triêu VNĐ. Nghiên cứu này được thực hiện nhằm đánh giá sự hài lòng của NVYT đối với các dạng thuốc sevoflurane đang lưu hành tại Việt Nam. 
II. ĐỐI TƯợNG VÀ PHƯƠNG PHÁP NGHIÊN CỨU

Đối tương nghiên cứu: Nhân viên y tế tham gia trực tiếp quá trình gây mê trong phẫu thuật bao gồm bác sĩ và kỹ thuật viên gây mê tại các bệnh viện tham gia nghiên cứu.

\section{Phương pháp nghiên cứu}

Thiết kế nghiên cứu. Nghiên cứu đa trung tâm với thiết kế mô tả cắt ngang. Dữ liệu được thu thập bằng phiếu khảo sát về mức độ quan trọng và sự hài lòng của từng tiêu chí trong lựa chọn thuốc gây mê đối với bác sĩ và sử dụng thuốc gây mê đối với kỹ thuật viên gây mê.

Mẫu nghiên cứu. Toàn bộ bác sĩ gây mê thỏa tiêu chí lựa chọn và không vi phạm tiêu chí loại trừ tại các địa điểm nghiên cứu trong thời gian lấy mẫu 01/03/2020 đến 30/05/2020.

Tiêu chí lưa chơn: Bác sĩ gây mê tham gia trực tiếp vào ca phẫu thuật

Có quyền guyết định loại thuốc gây mê sử dụng trong phẩu thuật

Đồng ý tham gia nghiên cứu

Tiêu chí loại trừ: Không hoàn thiện phiếu khảo sát

Quy trình nghiên cứu: Quy trình nghiên cứu được trình bày trong hình 1.

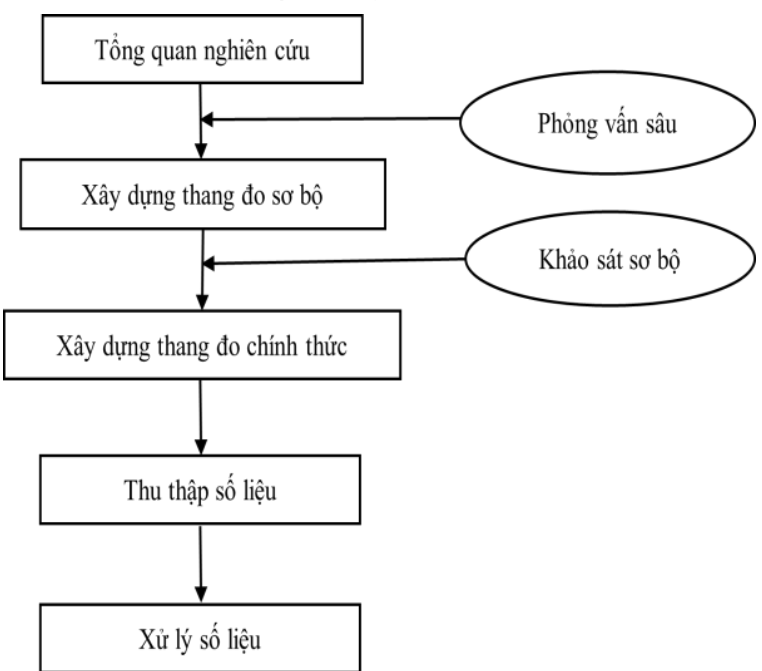

Hình 1. Quy trinh nghiên cứu

Biến số nghiên cứu. Sứ hài lòng và mức độ quan trọng được đánh giá trên thang điểm Likert 5 mức độ với 1 - rất không hài lòng/rất không quan trọng đến 5 - rất hài lòng/rất quan trọng

Tổng điểm sự hài lòng tổng thể được đánh giá dựa trên công thức:

$$
\mathrm{UT}_{\mathrm{n}}=\frac{\mathrm{S}_{1} * \mathrm{I}_{1}+\mathrm{S}_{2} * \mathrm{I}_{2}+\ldots+\mathrm{S}_{11} * \mathrm{I}_{11}}{\mathrm{I}_{1}+\mathrm{I}_{2}+\ldots+\mathrm{I}_{11}}
$$

Trong đó: $U T_{n}-$ sự hài lòng tổng thể đối với thuốc gây mê của mỗi bác sĩ;
$\mathrm{S}_{1}, \mathrm{~S}_{2}, \ldots, \mathrm{S}_{11}-$ điểm số hài lòng từng tiêu chí; $\mathrm{I}_{1}, \mathrm{I}_{2}, \ldots, \mathrm{I}_{11}$ - điểm số quan trọng từng tiêu chí.

Địa điểm và thời gian nghiên cứu:

Địa điểm nghiên cứu: nghiên cứu được thực hiện tại các bệnh viện tại Hà Nội, Huế và TP.HCM, trong đó bệnh viện được chia làm chia làm 2 loại: bệnh viện chỉ sử dụng một loại sevoflurane và bệnh viện sử dụng nhiều loại sevoflurane. Những bệnh viện thực hiện nghiên cứu đảm bảo các tiêu chí trên như sau:

- Bệnh viện sử dụng một loại sevoflurane: Bệnh viện Đại học Y dược Thành phố Hồ Chí Minh, Bệnh viện Hữu Nghị, Bệnh viện Việt Đức

- Bệnh viện sử dụng nhiều loại sevoflurane: Bệnh viện Chợ Rẫy, Bệnh viện Đại học Y dược Huế

- Thời gian nghiên cứu: 01/10/2019 đến 30/09/2020

Thống kê và xử lý dữ liệu. Số liệu được thống kê và xử lý bằng phần mềm SPSS 20.0 với độ tin cậy $95 \%$ với các phép kiểm thống kê phù hợp. Số liệu được trình bày dưới dạng hình và bảng.

\section{KẾT QUẢ NGHIÊN CứU}

Đặc điểm mẫu nghiên cứu

Đặc điểm bác sĩ gây mê. Khảo sát mẫu nghiển cứu bao gồm 96 bác sĩ gây mê tại 5 bệnh viện (Đại học Y Dược Huế, Đại học Y Dược TP.HCM, Chợ Rẫy, Hữu Nghị, Việt Đức), đề tài ghi nhận các đặc điểm nhân khẩu và nghề nghiệp trong bảng 1 .

Bảng 1. Đặc điểm nhân khẩu và nghề nghiệp của bác sĩ gây mê

\begin{tabular}{|c|c|c|c|}
\hline \multicolumn{2}{|c|}{ Đặc điểm } & \multirow{2}{*}{\begin{tabular}{|c|c|}
$\begin{array}{c}\text { Tân số } \\
\text { (Tỷ lệ } \\
\text { \%) }\end{array}$ \\
$41(42,7)$
\end{tabular}} & \multirow{2}{*}{ 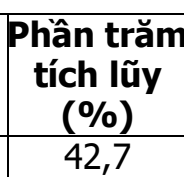 } \\
\hline \multirow{2}{*}{ Giới tính } & Nũ̃ & & \\
\hline & Nam & $55(57,3)$ & 100,0 \\
\hline \multirow{3}{*}{$\begin{array}{l}\text { Hoc } \\
\text { vẩn }\end{array}$} & Đại học & $20(20,8)$ & 20,8 \\
\hline & Nội trú & $14(14,6)$ & 35,4 \\
\hline & Sau Đai hoc & $62(64,6)$ & 100,0 \\
\hline \multirow{4}{*}{$\begin{array}{l}\text { Chức } \\
\text { vụ }\end{array}$} & Nhân viên & $77(80,2)$ & 80,2 \\
\hline & Phó khoa & $7(7,3)$ & 87,5 \\
\hline & Trưởng khoa & $3(3,1)$ & 90,6 \\
\hline & Chức vụ khác & $9(9,4)$ & 100,0 \\
\hline \multirow{4}{*}{$\begin{array}{l}\text { Thâm } \\
\text { niên }\end{array}$} & Dưới 3 năm & $32(33,3)$ & 33,3 \\
\hline & 3 - 5 năm & $15(15,6)$ & 49,0 \\
\hline & 5 - 10 năm & $20(20,8)$ & 69,8 \\
\hline & Trên 10 năm & $29(30,2)$ & 100,0 \\
\hline \multirow{3}{*}{$\begin{array}{l}\text { Tỷ lệ sử } \\
\text { dụng các } \\
\text { dạng thuốc } \\
\text { sevoflurane }\end{array}$} & $\begin{array}{c}\text { Biệt dược gốc } \\
\text { (BDG) }\end{array}$ & $96(100,0)$ & \\
\hline & $\begin{array}{l}\text { Generic } 1 \\
(\mathrm{G} \times 1)\end{array}$ & $69(71,9)$ & \\
\hline & Generic 2(Gx 2) & $2(2,1)$ & \\
\hline
\end{tabular}


VIETNAM MEDICAL JOURNAL N²2 - JANUARY - 2021

\begin{tabular}{|c|c|}
\hline Tuối & GTTB \pm ĐLC \\
\hline Số ca phấu thuật tham gia \\
$\begin{array}{c}\text { trong ngày } \\
\text { Tỷ lệ ca phâ̂u thuật nội soi }\end{array}$ & $35,55 \pm 8,78$ \\
\hline Tỷ lệ ca phâ̂u thuật cấp cứu & $25,00 \pm 2,89$ \\
\hline
\end{tabular}

GTTB: Giá trị trung bình; ĐLC: Đô lệch chuấn

Theo bảng 1, mẫu nghiên cứu bác sĩ gây mê có đặc điểm sau: tỷ lê nam : nữ là $1,34: 1$ với đô tuổi trung bình $35,55 \pm 8,78$ tuổi. Phần lớn các bác sĩ đều có trình đô sau đại học $(64,6 \%)$, tiếp theo là trình độ đại học $(20,8 \%)$, ít nhất là nội trú $(14,6 \%)$. Phần lớn các bác sĩ là nhân viên $(80,2 \%)$, phó khoa chiếm $7,3 \%$ và trưởng khoa chiếm $3,1 \%$. Phần lớn các bác sĩ có thâm niên dưới 3 năm (33,3\%), tiếp theo là các bác sĩ có thâm niên trên 10 năm $(30,2 \%)$ và thâm niên từ 5-10 năm $(20,8 \%)$. Các bác sĩ có thâm niên từ 3 -5 năm chiếm tỷ lệ thấp nhất với 15,6\%. Tất cả các bác sĩ gây mê được khảo sát đều đã sử dụng sevoflurane BDG trong khi thuốc Gx được ít bác sĩ sử dụng hơn $(71,9 \%$ và $2,1 \%)$. Các bác sĩ tham gia trung bình $6,00 \pm 2,89$ ca phấu thuật 1 ngày với tỷ lệ ca phấu thuật nội soi là $34,88 \pm$ $21,54 \%$ và tỳ lệ ca phẫu thuât cấp cứu là 25,04 $\pm 16,71 \%$ trên tổng số ca phẩu thuật.

Đặc điểm kỹ thuật viên gây mê. Khảo sát mẫu nghiên cứu gồm 118 kỹ thuật viên gây mê ở 5 bênh viên (Đai hoc $Y$ Dược Huế, Đai hoc $Y$ Dược TP.HCM, Chợ Rẫy, Hữu Nghị, Viểt Đức), nghiên cứu ghi nhận đặc điểm của mẫu được trình bày trong bảng 2 .

Bảng 2. Đăc điểm nhân khẩu và nghề nghiệp của kỹ் thuật viên gây mê

\begin{tabular}{|c|c|c|c|}
\hline \multicolumn{2}{|c|}{ Đặc điểm } & $\begin{array}{c}\text { Tân số } \\
\text { (tỷ lệ \%) }\end{array}$ & $\begin{array}{c}\text { Phân trăm } \\
\text { tích luỹ } \\
\text { (\%) }\end{array}$ \\
\hline \multirow{2}{*}{$\begin{array}{c}\text { Giới } \\
\text { tính }\end{array}$} & Nữ & $72(61,0)$ & 61,0 \\
\cline { 2 - 4 } & Nam & $46(39,0)$ & 100,0 \\
\hline \multirow{2}{*}{$\begin{array}{c}\text { Trình } \\
\text { độ hộ } \\
\text { vânn }\end{array}$} & Cao đằng & $32(27,1)$ & 27,1 \\
\cline { 2 - 4 } & Đại học & $60(50,8)$ & 78,0 \\
\cline { 2 - 4 } & Sau đại học & $1(0,8)$ & 78,8 \\
\cline { 2 - 4 } & Trung cấp & $25(21,2)$ & 100,0 \\
\hline \multirow{2}{*}{$\begin{array}{c}\text { Chức } \\
\text { vụ }\end{array}$} & Nhân viên & $117(99,2)$ & 99,2 \\
\cline { 2 - 4 } & Tổ trưởng & $1(0,8)$ & 100,0 \\
\hline \multirow{3}{*}{$\begin{array}{c}\text { Thâm } \\
\text { niên }\end{array}$} & $3-5$ năm & $15(12,7)$ & 12,7 \\
\cline { 2 - 4 } & $5-10$ năm & $31(26,3)$ & 39,0 \\
\cline { 2 - 4 } & Dưới 3 năm & $13(11,0)$ & 50,0 \\
\cline { 2 - 4 } & Trên 10 năm & $59(50,0)$ & 100,0 \\
\hline Tỷ lệ sử & BDG & $117(99,2)$ & \\
\hline
\end{tabular}

\begin{tabular}{|r|c|c|c|}
\hline $\begin{array}{r}\text { dụng các } \\
\text { dạng thuốc } \\
\text { sevoflurane }\end{array}$ & Gx 1 & $104(88,1)$ & \\
\cline { 2 - 4 } & Gx 2 & $11(9,3)$ & \\
\hline \multicolumn{2}{|c|}{ Đặc điểm } & $\begin{array}{c}\text { GTTB } \pm \\
\text { ĐLC }\end{array}$ & $\begin{array}{c}\text { GTNN- } \\
\text { GTLN }\end{array}$ \\
\hline \multicolumn{2}{|r|}{ Tuổi (tuổi) } & $\begin{array}{c}34,23 \pm \\
7,48\end{array}$ & $23-59$ \\
\hline
\end{tabular}

Ghi chú: GTNN: Giá trị nhỏ nhất; GTLN: Giá trị lớn nhất; GTTB: Giá trị trung bình; ĐLC: Độ lệch chuẩn; BDG - Biệt dược gốc, Gx - Generic

Theo bảng 2, mẫu nghiên cứu kỹ thuật viên gây mê có đặc điểm sau: tỷ lệ nam: nữ là $1: 1,57$ với độ tuổi trung bình là $34,23 \pm 7,48$; phần lớn kỹ thuật viên gây mê có trình độ đại học $(50,8 \%)$, tiếp theo là trình độ cao đẳng và trung cấp $(27,1 \%$ và $21,2 \%$ tương ứng), trình độ sau đại học chiếm tỷ lệ thấp nhất với $0,8 \%$. Có 1 kỹ thuật viên được khảo sát là tổ trưởng, còn lai đều là nhân viên với tỷ lệ là 99,2\%. Phần lớn kỹ thuật viên gây mê có thâm niên trên 10 năm $(50,0 \%)$, tiếp theo là thâm niên từ 5-10 năm $(26,3 \%)$, từ 3-5 năm $(12,7 \%)$ và ít nhất là thâm niên dưới 3 năm (11,0\%). Nghiên cứu ghi nhận sevoflurane BDG là thuốc được hầu hết các kỹ thuật viên gây mê sử dụng $(99,2 \%)$ trong khi thuổc $\mathrm{Gx}$ đước sử dụng ít hơn với tỷ lê $88,1 \%$ và 9,3\% tương ứng.

Đánh giá tổng điểm hài lòng của bác sĩ đối với các dạng thuốc gây mê

Mức đô quan trọng của các tiêu chí sử dụng thuốc gây mê. Khảo sát tỷ lệ xem xét và mức độ quan trọng của các tiêu chí trong lựa chọn các dạng thuốc sevoflurane đối với bác sĩ gây mê, nghiên cứu ghi nhận kết quả được trình bày trong hình 2 .

Theo hình 2, nghiên cứu ghi nhận tỷ lệ xem xét các tiêu chí trong lựa chọn các dạng thuốc sevoflurane dao động trong khoảng 84,4 $96,9 \%$. Trong đó 2 tiêu chí được nhiêu bác sĩ gây mê lựa chọn nhất là "ít gây biến chứng" và "tiết kiệm thời gian cho nhân viên y tế" $(96,9 \%)$, tiêu chí được ít xem xét nhất là "quan sát được thuốc còn trong chai" (84,4\%). Mức độ quan trọng của các tiêu chí trong lựa chọn thuốc sevoflurane dao động từ 3,20 - 4,46 trên thang điểm Likert 5 mức độ. Trong đó tiêu chí có mức độ quan trọng cao nhất là "ít gây biến chứng" $(4,46)$ và ít quan trọng thấp nhất là "quan sát được thuốc còn trong chai" $(3,20)$, các tiêu chí còn lại có mức độ từ quan trọng đến khá quan trọng (dao động từ 3,50 đến 4,26). 


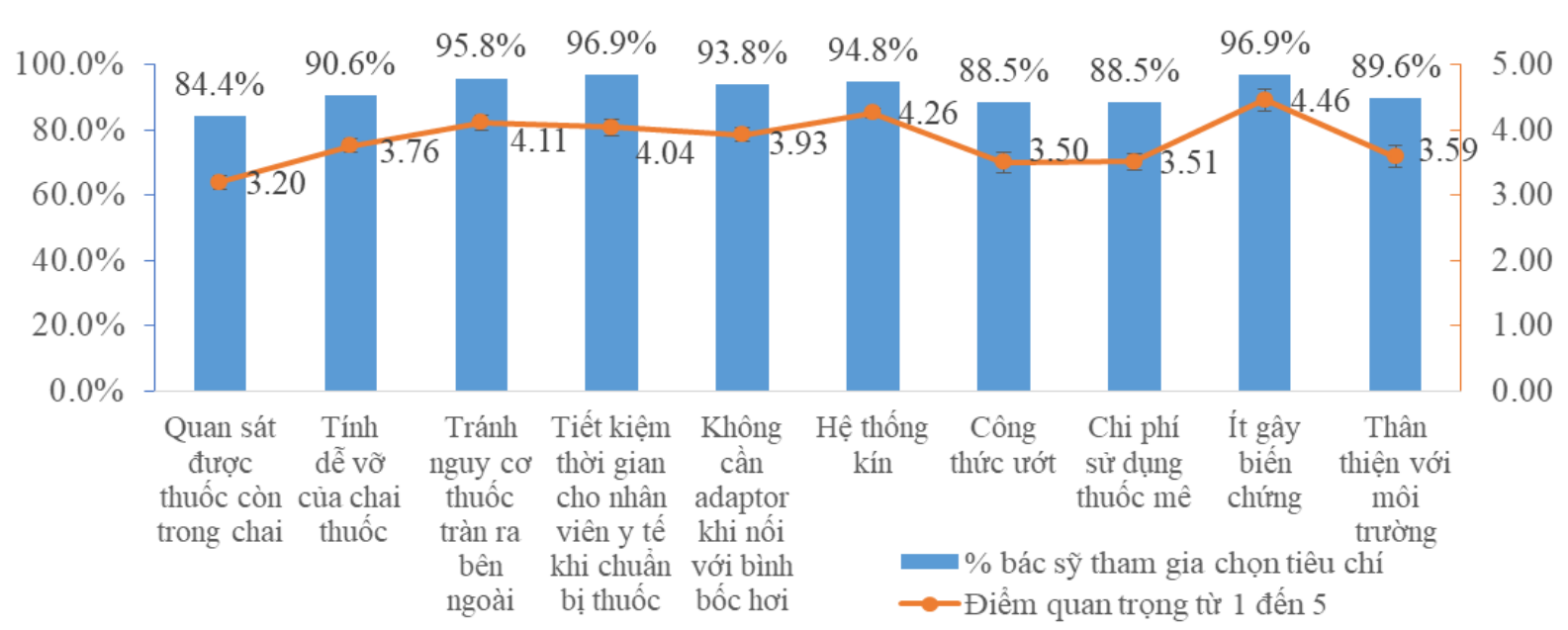

Hình 2. Tỷ lệ xem xét và mức độ quan trọng các tiêu chí sử dụng sevoflurane ở bác sĩ gây mê

Sự hài lòng đối với các tiêu chí lựa chọn thuốc gây mê. Khảo sát sự hài lòng của bác sĩ gây mê đối với các dạng thuốc sevoflurane trên từng tiêu chí đối với các dạng thuốc sevoflurane, kết quả được trình bày trong bảng 3 .

Bảng 3. Sự hài lòng của bác sĩ trên từng tiêu chí đôi với các dạng sevoflurane

\begin{tabular}{|c|c|c|c|c|}
\hline \multirow[t]{2}{*}{ Tiêu chí } & $\begin{array}{c}\text { Sevoflurane } \\
\text { BDG }\end{array}$ & $\begin{array}{c}\text { Sevoflurane } \\
\text { Gx }\end{array}$ & \multirow{2}{*}{$\begin{array}{c}\text { Khoảng } \\
\text { chênh lệch } \\
\text { (Độ tin cậy } \\
95 \% \text { ) }\end{array}$} & \multirow{2}{*}{$\begin{array}{c}\text { p- } \\
\text { value }\end{array}$} \\
\hline & GTTB \pm ĐLC & $\begin{array}{l}\text { GTTB } \pm \\
\text { ĐLC }\end{array}$ & & \\
\hline Quan sát được thuốc còn trong chai & $4,30 \pm 0,73$ & $3,40 \pm 0,99$ & $0,61-1,19$ & 0,000 \\
\hline Tính dề vỡ của chai thuốc & $4,38 \pm 0,69$ & $3,95 \pm 0,76$ & $0,19-0,66$ & 0,000 \\
\hline Tránh nguy cơ thuốc tràn ra bên ngoài & $4,43 \pm 0,65$ & $3,70 \pm 0,89$ & $0,48-0,99$ & 0,000 \\
\hline $\begin{array}{c}\text { Tiết kiệm thời gian cho NVYT khi chuấn bị } \\
\text { thuốc gây mê }\end{array}$ & $4,40 \pm 0,66$ & $3,67 \pm 0,90$ & $0,47-0,99$ & 0,000 \\
\hline Không cần adaptor khi nối với bình bốc hơi & & $3,32 \pm 0,92$ & $0,88-1,39$ & 0,000 \\
\hline Hệ thống kín giúp an toàn cho NVYT & $4,40 \pm 0,67$ & $3,87 \pm 0,80$ & $0,30-0,76$ & 0,000 \\
\hline Công thức ướt giúp an toàn cho NVYT & $4,26 \pm 0,74$ & $3,47 \pm 0,80$ & $0,54-1,04$ & 0,000 \\
\hline Chi phí sử dụng thuốc mê hợp lý & $3,89 \pm 0,93$ & $3,80 \pm 0,84$ & $-0,19-0,39$ & 0,510 \\
\hline İt gây biến chứng & $4,27 \pm 0,68$ & $3,76 \pm 0,63$ & $0,30-0,72$ & 0,000 \\
\hline Thân thiện với môi trường & $4,00 \pm 0,89$ & $3,51 \pm 0,79$ & $0,22-0,77$ & 0,001 \\
\hline Tổng điểm hài lòng & $4,29 \pm 0,53$ & $3,67 \pm 0,58$ & $0,45-0,79$ & 0,000 \\
\hline
\end{tabular}

Ghi chú: GTTB: giá trị trung bình; ĐLC: độ lệch chuẩn; NVYT: Nhân viên y tế

Theo bảng 3, nghiên cứu ghi nhận điểm số hài lòng trung bình của bác sĩ đối với sevoflurane BDG dao động từ 3,89 đến 4,46 với $9 / 10$ tiêu chí có mức độ hài lòng trên 4,00 trong khi sevoflurane Gx có điểm số hài lòng dao động từ 3,32 đến 3,87 và không có tiêu chí nào có điểm số hài lòng trên 4,00 . Như vậy mức độ hài lòng của bác sĩ cao hơn đối với sevoflurane BDG so với Gx ở tất cả các tiêu chí (trừ tiêu chí chí chi phí sử dụng thuốc gây mê hợp lý). Sự khác biệt này có ý nghĩa thống kê với $p<0,001$. Sự khác biệt lớn nhất được ghi nhận ở tiêu chí "không cần adaptor khi nối với bình bốc hơi", đây cũng là tiêu chí điểm số hài lòng của bác sĩ đối với sevoflurane BDG được đánh giá có mức độ hài lòng cao nhất và sevoflurane Gx có mức độ hài lòng thấp nhất (4,46 so với 3,32, tương ứng).

Đối với tiêu chí "chi phí sử dụng thuốc gây mê", đề tài không ghi nhận sự khác biệt có ý nghĩa thống kê giữa 2 dạng thuốc sevoflurane $B D G$ và $G x(p=0,510>0,05)$. Như vâyy đối với bác sĩ, chi phí sử dụng thuốc gây mê là tiêu chí không quan trọng và giá thành thấp của các thuốc Gx cũng không làm gia tăng sự hài lòng của bác sĩ gây mê khi lựa chọn sử dụng. Đối với tiêu chí "ít gây biến chứng", tiêu chí được nhiều bác sĩ xem xét nhất và có mức độ quan trọng nhất, sự hài lòng của bác sĩ cao hơn ở BDG so với $\mathrm{Gx}(4,27$ so với 3,76, $\mathrm{p}=0,000<0,05)$.

Như vậy, bác sĩ gây mê có tổng điểm hài lòng 
cao hơn ở sevoflurane BDG so với $\mathrm{Gx}$ (4,29 so với 3,67; $p=0,000<0,05)$.

Đánh giá tổng điểm hài lòng của kỹ thuật viên gây mê đối với các dạng thuốc gây mê

Mức độ quan trọng của các tiêu chí sử dụng thuốc gây mê. Khảo sát tỷ lệ xem xét và mức độ quan trọng của các tiêu chí đánh giá sự hài lòng của kỹ thuật viên đối với các dạng thuốc sevoflurane, nghiên cứu ghi nhận kết quả được trình bày trong hình 3 .

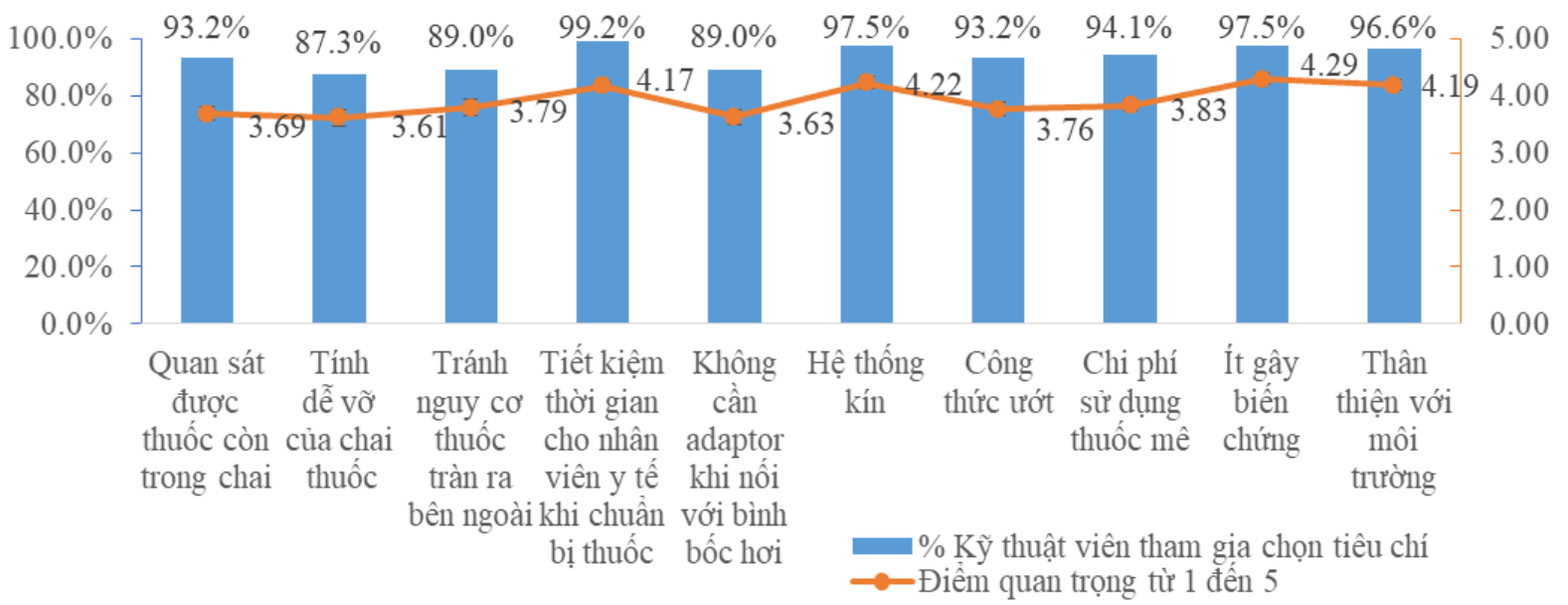

Hình 3. Mức độ quan trọng của các tiêu chí sử dụng thuốc gây mê sevoflurane của KTV gây mê

Theo hình 3, nghiên cứu ghi nhận tỷ lệ xem xét các tiêu chí trong sử dụng các dạng thuốc sevoflurane dao động trong khoảng 87,3\% $99,2 \%$. Trong đó tiểu chí "tiết kiệm thời gian cho nhân viên y tế" được nhiều kỹ thuật viên gây mê xem xét nhất (chiếm 99,2\%). Tiêu chí "tính dễ võ của chai thuốc" được ít kỹ thuật viên xem xét nhất (chiếm 87,3\%). Mức độ quan trọng của các tiêu chí trong sử dụng thuốc sevoflurane dao động từ 3,69-4,29 (trên thang điểm 5). Trong đó tiêu chí "ít gây biến chứng" có mức độ quan trọng cao nhất với 4,29 điểm và "tính dễ vỡ của chai thuốc" có mức độ quan trọng thấp nhất với 3,61 điểm. Các tiêu chí còn lại có mức độ quan trọng dao động từ 3,69 đến 4,22; trong đó tiêu chí "tiết kiệm thời gian cho nhân viên y tế" được nhiều kỹ thuật viên xem xét lựa chọn nhất nhưng có mức độ quan trọng trung bình (với điểm quan trong 4,17/5).

Sư hài lòng đối với các tiêu chí sử dung thuốc gây mê. Khảo sát sự hài lòng của KTV gây mê đối với các dạng thuốc sevoflurane trên từng tiêu chí, nghiên cứu ghi nhận kết quả được trình bày trong bảng 4 .

Bảng 4. Sự hài lòng của kỹ thuật viên trên từng tiêu chí đôí với các dạng sevoflurane

\begin{tabular}{|c|c|c|c|c|}
\hline \multirow[b]{2}{*}{ Tiêu chí } & \multicolumn{2}{|c|}{ Sevoflurane BDG Sevoflurane Gx } & \multirow{2}{*}{$\begin{array}{l}\text { Khoảng tin } \\
\text { cậy (Độ tin cậy } \\
95 \%)\end{array}$} & \multirow[b]{2}{*}{ p-value } \\
\hline & GTTB \pm ĐLC & GTTB \pm ĐLC & & \\
\hline Quan sát được thuốc còn trong chai & $4,08 \pm 0,75$ & $3,11 \pm 1,25$ & $0,69-1,26$ & 0,000 \\
\hline Tính dề võ của chai thuốc & $31 \pm 0,60$ & $4,08 \pm 0,73$ & $0,05-0,43$ & 0,013 \\
\hline Tránh nguy cơ thuốc tràn ra bên ngoài & $4,21 \pm 0,69$ & $3,54 \pm 1,03$ & $0,42-0,92$ & 0,000 \\
\hline $\begin{array}{l}\text { Tiết kiệm thời gian cho NVYT khi } \\
\text { chuẩn bị thuốc gây mê }\end{array}$ & $4,22 \pm 0,60$ & $3,71 \pm 0,88$ & $0,30-0,71$ & 0,000 \\
\hline $\begin{array}{c}\text { Không cần adaptor khi nối với bình } \\
\text { bốc hơi }\end{array}$ & $4,23 \pm 0,73$ & 3 & 0,6 & 0,000 \\
\hline Hệ thống kín giúp an toàn cho NVYT & $=0,76$ & $\pm 0,94$ & 0,79 & 0,000 \\
\hline Công t & 70 & $\pm 0,88$ & $0,26-0,70$ & \\
\hline Chi phí s & & $\pm 0,75$ & $-0,16-0,23$ & 0,714 \\
\hline It & $\pm 0,63$ & $\pm 0,68$ & $0,03-0,38$ & 0,021 \\
\hline Thân thiện v & $3,93 \pm 0,98$ & $3,60 \pm 1,06$ & $0,05-0,60$ & 0,020 \\
\hline Sự hài lòng tổng & $3,83 \pm 0,81$ & $3,17 \pm 1,35$ & $0,37-0,94$ & 0,000 \\
\hline
\end{tabular}

Ghi chú: GTTB: giá trị trung bình; ĐLC: độ lệch chuẩn; NVYT: Nhân viên y tế 
Theo bảng 4, nghiên cứu ghi nhận điểm số hài lòng trung bình của sevoflurane BDG dao động từ 3,76 đến 4,31 với 8/10 tiêu chí có mức độ hài lòng trên 4,00 trong khi sevoflurane Gx có điểm số hài lòng dao động từ 3,11 đến 4,08 và có $1 / 10$ tiêu chí có điểm số hài lòng trên 4,00 (tiêu chí "tính dễ võ của chai thuốc"). Như vậy, điểm số hài lòng của KTV gây mê cao hơn ở sevoflurane BDG so với Gx ở tất cả các tiêu chí. Trong đó sự khác biệt có ý nghĩa thống kê được ghi nhận ở hầu hết các tiêu chí $(p<0,05)$, trừ tiêu chí "chi phí sử dụng thuốc mê hợp lý". Sự khác biệt lớn nhất giữa sevoflurane BDG so với Gx được ghi nhận ở tiêu chí "quan sát được thuốc còn trong chai", đây cũng là tiêu chí mà sevoflurane Gx có mức độ hài lòng thấp nhất (3,11 điểm).

Đối với tiêu chí "chi phí sử dụng thuốc gây mê", nghiên cứu không ghi nhận sự khác biệt có ý nghĩa thống kê giữa 2 dạng thuốc sevoflurane BDG và $G x(p=0,714>0,05)$. Như vậy cũng như bác sĩ gây mê, chi phí thuốc thấp hơn của $G x$ không nâng cao sự hài lòng trong sử dụng thuốc của KTV gây mê. Nghiên cứu cũng ghi nhận sự khác biệt có ý nghĩa thống kê trong điểm số hài lòng của sevoflurane BDG so với Gx đối với tiêu chí "tiết kiệm thời gian cho nhân viên y tế khi chuẩn bị thuốc gây mê", tiêu chí có nhiều kỹ thuật viên xem xét nhất $(4,22$ so với 3,71 ; $p=0,000)$ và tiêu chí "ít gây biến chứng", tiêu chí có mức độ quan trọng nhất $(4,14$ so với 3,93 ; $\mathrm{p}=0,000$ ).

Như vậy, kỹ thuật viên gây mê có điểm số hài lòng tổng thể cao hơn ở sevoflurane BDG so với Gx $(3,83$ so với 3,17$)$. Sự khác biệt này có ý nghĩa thống kê với $p=0,000$.

\section{BÀN LUẬN}

Với tính an toàn, độ ổn định, thành phần thuốc và hiệu quả lâm sàng tương đồng giữa sevoflurane $B D G$ và $G x$ được chứng minh trong nhiều nghiên cứu ${ }^{(3-5)}$, đề tài ghi nhận sự khác biệt trong sự hài lòng ở NVYT (bác sĩ và kỹ thuật viển gây mể), trong đó NVYT có tổng điểm hài lòng cao hơn ở hầu hết các tiêu chí trừ tiêu chí chi phí sử dụng thuốc gây mê. Điều đó cho thấy ngoài những tiêu chí về an toàn, hiệu quả lâm sàng và độ ổn định, nhiều tiêu chí khác cần được xem xét trong lựa chọn thuốc gây mê, đặc biệt là những tiêu chí liên quan đến an toàn cho NVYT trong quá trình sử dưng (quan sát được thuốc còn trong chai, tính dễ vỡ của chai thuốc, tránh nguy cơ thuốc tràn ra bên ngoài, hệ thống kín, công thức ướt, thân thiện với môi trường). Những tiêu chí này được đánh giá cao hơn ở sevoflurane BDG so với Gx, điều đó giải thích cho sự khác biệt có ý nghĩa thống kê trong sự hài lòng của NVYT đối với sevoflurane BDG so với Gx.

Ngoài ra, tiêu chí "chi phí sử dụng thuốc gây mê hợp lý" đều thấp ở cả dạng BDG và Gx và không ghi nhận sự khác biệt có ý nghĩa thống kê giữa 2 dạng thuốc. Điều đó cho thấy đối với NVYT giá thuốc không quá quan trọng trong lựa chọn thuốc gây mê, chi phí sử dụng thuốc thấp hơn cũng không làm nâng cao sự hài lòng của NVYT.

Điểm hài lòng của bác sĩ nhìn chung đều cao hơn kỹ thuật viên gây mê. Điều này có thể được giải thích bởi kỹ thuật viên là người trực tiếp bị ảnh hưởng trong quá trình thao tác chuẩn bị thuốc mê với nguy cơ thuốc phát tán ra môi trường bên ngoài(6) vì vậy điểm hài lòng của KTV gây mê thấp hơn.

Mức độ quan trọng của các tiêu chí lựa chọn và sử dụng thuốc khác biệt ở bác sĩ và KTV gây mê, trong đó đối với bác sĩ gây mê "ít gây biến chứng" là tiêu chí quan trọng nhất trong lựa chọn với điểm quan trọng cao nhất, đối với KTTV gây mê "tiết kiệm thời gian cho nhân viên y tế khi chuẩn bị thuốc" là tiêu chí có điểm quan trọng cao nhất, tiếp theo là tiêu chí "hệ thống kín" và "thân thiện với môi trường". Như vậy đối với bác sĩ quan trọng nhất là an toàn người bệnh, đối với KTV tiện dụng và an toàn khi sử dụng cho nhân viên y tế là quan trọng nhất.

Năm 1996, báo cáo về chất lỏng sevoflurane trong một số chai có màu đục và mùi hăng, điều tra cho thấy chúng có độ axit cao và chứa axit flohydric (HF), một loại axit dễ bay hơi độc hại (7). Kể từ đó, nước được thêm vào công thức sevoflurane BDG (công thức ướt) đã giúp ngăn ngừa các tương tác phân hủy sevoflurane trong chai thủy tinh và thiết bị gây mê(7). Nghiên cứu sự hài lòng của NVYT ở tiêu chí này cho thấy bác sĩ và $K T V$ gây mê có điểm hài lòng cao hơn ở sevoflurane BDG so với Gx. Điều này có thể được giải thích bởi công thức ướt được bổ sung cho sevoflurane BDG và không có trong sevoflurane Gx, mặc dù tiêu chí này có tỷ lệ xem xét và mức độ quan trọng trung bình.

Nghiên cứu đã đánh giá được sự hài lòng tổng thể dựa trên mức độ quan trọng và sự hài lòng của từng tiêu chí phù hợp với cách đánh giá sự hài lòng của Evangelos G. và cộng sự(8). Nghiên cứu đã ghi nhận được các tiêu chí ảnh hưởng đến sự hài lòng của nhân viên y tế trong sử dụng thuốc gây mê và cho thấy có những tiêu chí rất được quan tâm nhưng mức độ quan trọng lại không cao (tiêu chí "tiết kiệm thời gian cho nhân viên y tế"). Đây cũng là nghiên cứu tiên 
phong trong đánh giá sự hài lòng của nhân viên y tế với các dạng thuốc của sevoflurane tại Việt Nam.

\section{KẾT LUÂN}

Với sự hài lòng của bác sĩ và kỹ thuật viên gây mê đối với sevoflurane BDG cao hơn sevoflurane Gx ở hầu hết các tiêu chí liên quan đến an toàn người bệnh, an toàn cho nhân viên $y$ tế, tổng điểm hài lòng của sevoflurane BDG cao hơn Gx ở cả bác sĩ lẫn kỹ thuật viên gây mê. Với cả hai đối tượng bác sĩ và kỹ thuật viên gây mê, điểm hài lòng đối với tiêu chí "chi phí sử dụng thuốc gây mê" không có sự khác biệt có ý nghĩa thống kê giữa sevoflurane BDG và GX.

\section{TÀI LIÊU THAM KHẢO}

1. Livertox: Clinical and Research Information on Drug-Induced Liver Injury (2014) "Drug Record: Sevoflurane", U.S. National Library of Medicine

2. Nandalan S. P., Eltringham R. J. , Fan Q. W. (2005). Cost-effectiveness of basal flow sevoflurane anaesthesia using the Komesaroff vaporizer inside the circle system. Anaesth Intensive Care, 33(5): p. 609-15.

3. Byon H. J., et al. (2015). An open-label comparison of a new generic sevoflurane formulation with original sevoflurane in patients scheduled for elective surgery under general anesthesia. Clin Ther, 37(4): p. 887-901.

4. Yamakage M., et al. (2007). Analysis of the composition of 'original' and generic sevoflurane in routine use. Br J Anaesth, 99(6): p. 819-23.

5. Portella A. A., et al. (2010). A double-blind comparative study between Generic Sevoflurane and Sevorane $^{\mathrm{TM}}$. Rev Bras Anestesiol, 60(5): p. 466-74.

6. Yasny J. S. and White J. (2012). Environmental implications of anesthetic gases. Anesth Prog, 59(4): p. 154-8.

7. Baker M. T. (2007). Sevoflurane: Are there differences in products?. Anesthesia \& Analgesia, 104(6): p. 1447-1451.

8. Grigoroudis E. and Spyridaki O. (2003). Derived vs. stated importance in customer satisfaction surveys. Operational Research, 3: p. 229-247.

\section{KẾT QUẢ ĐÎ̂̀U TRỊ PHẪU THUÂT BÊNNH NHÂN CHẤN THƯƠNG CộT SỐNG CỔ CAO BẰNG PHƯƠNG PHÁP NẸP CỔ CHẨM}

Nguyễn Viết Lực ${ }^{1}$, Ngô Thanh Tú2, Võ Văn Thanh ${ }^{1,2}$, Nguyễn Lê Bảo Tiến ${ }^{2}$

\section{TÓM TẮT}

Muc tiêu: Đánh giá kết quả điêu tri phẫu thuât bệnh nhân chấn thương cột sống cổ cao bằng phương pháp nẹp cổ chẩm. Phương pháp: Thiết kế theo phương pháp mô tả, nghiên cứu hồi cứu kết hợp tiến cứu trên 31 bênh nhân. Kết quả: Tỷ lề bệnh nhân đau cơ giảm tử $100 \%$ còn $27,5 \%$ và tỷ lệ co cứng cơ giảm $61,3 \%$ còn 27,5 (với $p=0,005$ ). Trước mổ, tỷ lế rối loạn cảm giác là $37,9 \%$ và tại thời điểm khám lại giảm còn $24,1 \%(p<0,005)$. Điểm VAS giảm từ $5,4 \pm$ 1,4 trước mổ xuống còn $2,1 \pm 1,3$ điểm sau mô (với $\mathrm{p}<0,005)$. Chỉ số JOA cải thiện từ 13,2 $\pm 3,6$ trước mổ lên $15,6 \pm 1,9$ điểm sau mổ $(p<0,005)$. Tỷ lệ liền xương của phẫu thuật và mức độ hài lòng của bệnh nhân lần lượt là $96,6 \%$ và $81 \%$. Kết luận: Sau phẫu thuật bằng phương pháp nẹp cổ chẩm, các bệnh nhân đều có sự phục hồi tốt các triệu chứng cơ năng và rối loạn cảm giác. Tỷ lệ liền xương của phẫu thuật và mức độ hài lòng của bệnh nhân cao.

Tư khóa: Chấn thương cột sống cổ cao, nẹp cổ chẩm, phẫu thuật.

${ }^{1}$ Đai hoc Y Hà Nôi

2Viện Chân thương Chỉnh Hinh, Bệnh viện Hữu nghị Viềt Đức

Chịu trách nhiệm chính: Nguyễn Lê Bảo Tiến

Email: bstiencsvd@gmail.com

Ngày nhân bài: 16.11.2020

Ngày phản biên khoa hoc: 5.01 .2021

Ngày duyệt bài: 18.01.2021

\section{SUMMARY}

THE RESULTS OF OF SURGICAL

TREATMENT WITH UPPER CERVICAL SPINE TRAUMA PATIENTS BY

OCCIPITOCERVICAL FUSION METHOD

Objective: To evaluate the results of surgical treatment with upper cervical spine trauma patients by occipitocervical fusion method. Methods: This is a descriptive, retrospective and prospective study of 31 patients. Results: The percentage of patients who muscle pain decreased from $100 \%$ to $27.5 \%$ and the percentage of muscle spasms decreased from $61.3 \%$ to $27.5 \%$ (with $p=0.005$ ). Before surgery, the dysaesthesia rate was $37.9 \%$ and it reduced to $24.1 \%$ at the time of re-examination $(p<0.005)$. The VAS point reduced from $5.4 \pm 1.4$ at preoperative time to $2.01 \pm 1.3$ at postoperative time (with $p<0.005$ ). The JOA index improved from $13.2 \pm 3.6$ before surgery to $15.6 \pm 1.9$ after surgery $(p<0.005)$. The percentage of bone knitting and the patient satisfaction were $96.6 \%$ and $81 \%$, respectively. Conclusion: After surgery by occipitocervical fusion method, the parents have good recovery of functional symptoms and dysaesthesia. The percentage of bone knitting and the patient satisfaction were high.

Keywords: Upper cervical spine trauma, occipitocervical fusion, surgical.

I. ĐẶT VẤN ĐỀ

Chấn thương cột sống cổ là chấn thương 